\title{
Grayanotoxin (Mad Honey) - Ongoing Consumption After Poisoning
}

\author{
Serkan Emre Eroğlu, Oğuz Urgan, Özge Ecmel Onur, Arzu Denizbaşı, Haldun Akoğlu \\ Department of Emergency Medicine, Marmara University Pendik Research and Training Hospital, istanbul, Turkey
}

\begin{abstract}
Background: Some honey types in certain geographical regions may cause toxic effects on people. This type of honey is known as "mad honey" in Turkey. The toxic ingredient of this honey is called Grayanotoxin I. The consumption of mad honey can cause severe bradycardia, hypotension, dizziness, nausea and vomiting.

Aims: Our study is aimed at analysing patients diagnosed with mad honey poisoning and their behaviour towards the consumption of this honey after diagnosis.

Study Design: Cross sectional study.

Methods: This cross-sectional study was based on complaints and findings of mad honey poisoning. Patient information and findings at the time of admission were compared with those at one month after discharge through telephone interviews. They were asked if either they or their relatives had continued consuming the same honey. Frequency data such as gender, purpose of honey consumption, first complaints and continuance of honey consumption are shown as number ( $n$ ) and percentage (\%). A Chi Square test was conducted to determine the difference between groups.

Results: 38 patients were participated in this study; 18 of the patients had to be followed up in a coronary intensive care unit. We were able to reach 34 patients by phone after discharge. It was found that 12 of 16 patients discharged after emergency unit observation or their close relatives were continuing to consume mad honey, whereas $16(88.9 \%)$ of the 18 patients under coronary intensive care had discontinued consuming mad honey. The difference in the continuation of mad honey consumption between patient groups followed-up in the intensive care unit and those discharged after emergency observation was statistically significant.
\end{abstract}

Conclusion: Hazards associated with and serious consequences following the consumption of mad honey must be clearly explained to patients who are found to be consuming mad honey.

Key Words: Honey, poisoning, grayanotoxin I

Received: 09.11.2012 Accepted: 21.02.2013

\section{Introduction}

Honey has an attractive taste and is easily consumed, and has therefore been used globally for thousands of years. However, it is known that certain types of honey in certain geographical regions may cause adverse effects on people. This type of honey, known as "mad honey" or "sour honey" was first identified by Xenephon, a historian and army commander in Athens. He demonstrated that a certain type of honey produced in the coastal Black Sea region caused poisoning among the soldiers during a campaign against the Persian King Ataxerses II around 400 BC (1). Today, the toxic ingredient of this honey is called Grayanotoxin I (Andromedotoxin) (2). The toxic honey is produced from R. Luteum and R. Ponticum, two members of Rhododendron family, and its consumption can cause severe bradycardia and hypotension (3). This kind of honey is often found in the northern regions of Turkey as well as in Nepal, Brazil and Japan. Our study is aimed at analysing the demographic, toxicological and therapeutic characteristics of patients diagnosed with mad honey poisoning and their behaviour towards the consumption of this honey after diagnosis.

\section{Material and Methods}

This is cross-sectional study that was conducted between April 2011 and April 2012 at Marmara University Medical School Pendik Training and Research Hospital Emergency Unit; the study was based on patients who had been admitted with complaints of mad honey poisoning. Emergency doctors recorded patient information on forms including age, gender, purpose of honey consumption, whether or not the patients were first-time consumers, first complaints at the time of admission, first hospital finding, time between consumption of honey and the emergence of symptoms and hospital unit that conducted the follow-up. Patients were ordered according to date of discharge and contacted by phone at the end of the first month after discharge. They were asked whether or not they or their relatives had continued to consume the same or a similar honey. The recorded data were analysed by using the SPSS 16.00 program; a Chi Square test was conducted to determine the difference between groups. Data with continuous values such as the age of patients and the time between consumption of honey and

This study was presented as a poster at the $7^{\text {th }}$ European Society for Emergency Medicine Congress, 3-6 October 2012, Antalya, Turkey. 
emergence of symptoms are shown as Average \pm Standard Deviation (Avg \pm SD) (smallest-biggest) value. Frequency data such as gender, purpose of honey consumption, first complaints and continuance of honey consumption are shown as number ( $\mathrm{n})$ and percentage (\%).

\section{Results}

It was found that a total of 38 patients had been diagnosed with mad honey poisoning during the study period. The average age of the patients was determined as $51 \pm 14.44$ (Maximum age: 79 , Minimum age: 22$) ; 21.1 \%(n=8)$ of patients were female and $78.9(n=30)$ were male. When they were asked why they had consumed honey, $36.8(n=14)$ answered that they consumed it as a breakfast food and the remaining 63.2 $(n=24)$ answered that they consumed it for its healing properties. When they were asked to define the term "healing", the only answer was immunisation. 10 (26.3\%) of the 38 patients said they had not consumed this honey before and 28 (73.7) of them said they had previously consumed it.

The two most common complaints of patients were dizziness (26 patients) and unconsciousness (26 patients). Other complaints were nausea-vomiting $(n=12)$ and chest pain $(n=2)$. The time between the consumption of honey and the emergence of symptoms was 30 to 180 minutes (Avg \pm SD, 83.68 \pm 49.887 min.). All of the 38 patients were admitted with complaints that were initially diagnosed, after a physical examination and a period of monitoring (electrocardiography and bed-side monitor), as sinus bradycardia (pulse rate interval 31 to 47 ).

$20(52.63 \%)$ of the patients were discharged after 8 to 25 hours of observation in an emergency unit, whereas 18 (47.36\%) were followed-up in the intensive care unit (ICU) for persistent bradycardia and to rule out acute coronary syndrome. However, none of them were followed-up for more than 2 days in the ICU. None of the patients were transferred to another healthcare facility and all of them were discharged with full recovery. Also, all of the patients survived from the time of admission to the end of the first 1 month period after discharge.

We tried to contact the above-mentioned 38 patients by phone after discharge and 34 of the 38 patients were contacted. When they were asked whether they or their close relatives continued consuming the honey that caused their mad honey poisoning, 14 (41.17\%) of the 34 patients said they continued to consume honey. The study also analysed the impacts of hospitalisation on the behaviours of patients towards the consumption of mad honey. It was found that 12 (75\%) of the 16 patients discharged after emergency unit observation or their family members continued consuming the so called mad honey and the remaining 4 (25\%) patients or their family members discontinued consuming it. However, 16 (88.9\%) of the 18 patients discharged after intensive care observation or their family members discontinued consuming the so-called mad honey and the remaining $2(11.1 \%)$ patients or their families continued consuming it. The difference regarding the continuation of mad honey consumption between these two patient groups was statistically significant $(p=0.001)$.

\section{Discussion}

The most important result of our study is regarding the continuance of mad honey consumption. This showed a significant difference between patient groups stratified according to the point of discharge: patients monitored in an intensive care unit or their relatives refrained from consuming mad honey again. The reason for this could be the fear experienced or the fact that hospitalisation in an intensive care unit can lead to the idea that they had a serious health problem. However, the patients that were only monitored in an emergency room continued to use it. This fact was not reported in any other previous study.

Grayanotoxin I (also called Andromedotoxin) is created only by plants of the Ericaceae family and accepted as the ingredient responsible for the poisoning. In the literature, high doses of Grayanotoxin have been reported in samples collected from patients that consumed two table spoons of mad honey and that were subsequently diagnosed with severe bradycardia and hypotension (4). This kind of honey, mostly produced in the Black Sea region of Turkey, is considered a healing honey and may not cause toxic effects in every consumer. However, it affects the majority of consumers. The most common symptoms of poisoning are hypotension and bradycardia $(5,6)$; bradycardia was the most common symptom in our study, too. Other common symptoms include perspiration, drowsiness and changes in consciousness (70\%); syncope (30\%); diplopia and blurred vision (20-80\%); and hypersalivation $(14 \%)(7,8)$. Symptoms start in an acute form and rarely last for more than 24 hours. The time of emergence of symptoms was found to be $2.8 \pm 1.8(0.5-9)$ hours by Gündüz et al. (9) and $1 \pm 0.5$ by Demircan et al. (10). The time determined by us was similar to the cases presented in these studies. Similar to these symptoms and findings, another parameter of importance was that the majority of cases were male; many other studies where mad honey poisoning had been examined also featured older male patients, similar to our study (9-12). The general age and gender distribution of cases can be explained by the fact that older male patients consumed mad honey for its healing properties as well as for sexual performance enhancing properties (10). This fact is supported by the fact that the majority of patients in our study were middleaged men. In order to clarify this fact, patients were asked to define the meaning of healing properties, which was defined as immunisation properties; however, this could be a result of their shyness towards speaking about sexual activity.

The various studies on mad honey poisoning feature no consensus as to the duration of hospital observation for patients that were admitted because of poisoning. Also, there are differences between the therapy and monitoring protocols of patients that were admitted to various healthcare institutions because of mad honey poisoning (9). Nevertheless, the study conducted by Gündüz et al. (9) clearly shows the difference between monitoring protocols applied to mad honey poisoning patients in various institutions. Although all of the 38 cases in our study were admitted with similar clinical findings (symptoms, electrocardiography findings etc.), some of 
them were discharged after observation in an emergency unit while others were discharged after observation in intensive care units. Nevertheless, none of the patients were followed for more than 2 days in these units. As can be seen, different therapy protocols and follow-up durations can be applied in different institutions, and we could not obtain a uniform protocol with regards to follow-up and therapy durations for mad honey poisoning, even though our study was conducted in a single institution.

Although morbidity can be seen during and after mad honey poisoning $(6,8,13)$, asystolia (14) and mortality (9-12) are rarely seen. We witnessed no mortalities in the cases examined in our study.

In particular, an increase in the consumption of natural products and products that are advertised as healing sources may lead to an increase in mad honey poisoning cases in emergency units. Therefore, mad honey poisoning must be considered a distinctive diagnosis for middle-aged men who are admitted to emergency units and diagnosed with unexplained bradycardia and hypotension. Furthermore, patients that are admitted to an emergency unit of a hospital because of mad honey poisoning must be specifically warned against the severe consequences of consuming mad honey.

Ethics Committee Approval: The Institutional Review Board approved the study. And, it was also conducted in accordance with the principles of the Declaration of Helsinki.

Informed Consent: Verbal consent was obtained after explaining the consent statement.

Peer-review: Externally peer-reviewed.

Author contributions: Concept - S.E., O.U.; Design - S.E., O.U., Ö.O.; Supervision - Ö.O., A.D., H.A.; Resource - O.U., S.E., Ö.O.; Materials S.E., A.D., Ö.O.; Data Collection\&/or Processing - S.E., O.U.; Analysis\&/ or Interpretation - S.E., H.A., Ö.O.; Literature Search - S.E., A.D., Ö.O.; Writing - S.E., Ö.O., O.U.; Critical Reviews - A.D., S.E., Ö.O.

Acknowledgements: Special thanks to Dr. Ray Guillery for English edition of the manuscript.

Conflict of Interest: No conflict of interest was declared by the authors.
Financial Disclosure: No financial disclosure was declared by the authors.

\section{References}

1. Gokçel T. in: Xenophon; Anabasis, Onbinlerin Dönüşü. 2nd edn. Istanbul: Sosyal Yayınlar; 1984. p. 143-4.

2. Sütlüpınar $N$, Mat $A$, Satganoğlu $Y$. Poisoning by toxic honey in Turkey. Arch Toxicol 1993;67:148-50. [CrossRef]

3. Onat FY, Yegen BC, Lawrence R, Oktay A, Oktay S. Mad honey poisoning in man and rat. Rev Environ Health 1991;9:3-9. [CrossRef]

4. Onat F, Yegen BC, Lawrence R, Oktay A, Oktay S. Site of action of grayanotoxins in mad honey in rats. J Appl Toxicol 1991;11:199201. [CrossRef]

5. Gossinger H, Hruby K, Pohl A, Davogg S, Sutterlutti G, Mathis $\mathrm{G}$. Poisoning with andromedotoxin-containing honey. Dtsch Med Wochenschr 1983;108:1555-8.

6. Dilber E, Kalyoncu M, Yaris N, Okten A. A case of mad honey poisoning presenting with convulsion: intoxication instead of alternative therapy. Turk J Vet Anim Sci 2002;32:361-2.

7. Yavuz H, Ozel A, Akkus I, Erkul I. Honey poisoning in Turkey. Lancet 1991;337:789-90. [CrossRef]

8. Yilmaz O, Eser M, Sahiner A, Altintop L, Yesildag O. Hypotension, bradycardia and syncope caused by honey poisoning. Resuscitation 2006;68:405-8. [CrossRef]

9. Gündüz A, Meriçé ES, Baydın A, Topbas M, Uzun H, Türedi S, et al. Does mad honey poisoning require hospital admission? Am J Emerg Med 2009;27:424-7. [CrossRef]

10. Demircan A, Keleş A, Bildik F, Aygencel G, Doğan NO, Gómez HF. Mad honey sex: therapeutic misadventures from an ancient biological weapon. Ann Emerg Med 2009;54:824-9. [CrossRef]

11. Ozhan H, Akdemir R, Yazici M, Gündüz H, Duran S, Uyan C. Cardiac emergencies caused by honey ingestion: a single centre experience. Emerg Med J 2004;21:742-4. [CrossRef]

12. Gunduz A, Turedi S, Uzun H, Topbas M. Mad honey poisoning. Am J Emerg Med 2006;24:595-8. [CrossRef]

13. Yildirim N, Aydin M, Cam F, Celik O. Clinical presentation of nonST-segment elevation myocardial infarction in the course of intoxication with mad honey. Am J Emerg Med 2008;26:108.e1-2.

14. Gunduz A, Durmus I, Turedi S, Nuhoglu I, Ozturk S. Mad honey poisoning related asystole. Emerg Med J 2007;24:592-3. [CrossRef] 